\title{
Author's reply to Wolstenholme and Sanfilippo and colleagues
}

\author{
Jennifer K Quint clinical lecturer and honorary consultant \\ Department of Non-Communicable Disease Epidemiology, London School of Hygiene and Tropical Medicine, London WC1E 7HT, UK
}

The responders have highlighted some important issues that merit further investigation. ${ }^{1-4}$

We agree with Wolstenholme that it seems counterintuitive to use $\beta$ blockers and $\beta$ agonists in patients with chronic obstructive pulmonary disease (COPD), but most patients in our study were prescribed cardioselective $\beta$ blockers, so theoretically $\beta$ blockade would not negate agonist activity in the lungs. Some studies have even suggested that $\beta$ blockers have beneficial effects on COPD and reduce exacerbations and mortality independent of cardiovascular risk. ${ }^{5}$ Although we agree that antimuscarinic agents are also effective bronchodilators, caution may be needed in this patient group owing to concomitant cardiac arrhythmias. This is an area in which more research is needed.

As Sanfilippo and colleagues state, primary percutaneous coronary intervention is an important and increasingly used treatment for ST-elevation myocardial infarction (STEMI). Our data (not published) suggested that patients with COPD are less likely than those without COPD to undergo percutaneous coronary intervention, and in our study the number of patients undergoing this intervention was too small to include in the analysis. We agree that percutaneous coronary intervention is becoming more common and may be an important factor. We are currently undertaking a large and more up to date study of patients with COPD using data from the Myocardial Ischemia National Audit Project (MINAP) to investigate this and several other factors.

Competing interests: I am the first author of the paper discussed in the response.

1 Rutten FH, Groenwold RHH. $\beta$ blockers for adults with chronic obstructive pulmonary disease. BMJ 2013;347:f7050. (25 November.)

2 Quint JK, Herrett E, Bhaskaran K, Timmis A, Hemingway H, Wedzicha JA, et al. Effect of $\beta$ blockers on mortality after myocardial infarction in adults with COPD: population based cohort study of UK electronic healthcare records. BMJ 2013;347:f6650. (22 November.)

3 Sanfilippo F, Santonocito C, Foex P. Major changes in practice and interpreting data from the past. BMJ 2014;348:g1131.

4 Wolstenholme RJ. Replacing $\beta$ agonists with antimuscarinic drugs in patients with COPD. WMJ 2014;348:g1108.

5 Rutten FH, Zuithoff NP, Hak E, Grobbee DE, Hoes AW. Beta-blockers may reduce mortality and risk of exacerbations in patients with chronic obstructive pulmonary disease. Arch Intern Med 2010;170:880-7.

Cite this as: BMJ 2014;348:g1132

๑ BMJ Publishing Group Ltd 2014 